\title{
Telemedicine During Covid-19 In Low-Resource Settings
}

\author{
Tatiana Roldan Ovalle* \\ Master's in health education, University of the Andes, Emergency Medicine Specialist - Santa Fe de Bogotá Foundation University \\ Hospital, Bogota Colombia
}

*Corresponding author: Tatiana Roldan Ovalle, master's in health education, University of the Andes. Emergency Medicine Specialist - Universidad Javeriana. Emergency Medicine Specialist - Santa Fe de Bogotá Foundation University Hospital. Clinical Professor of School of Medicine - Universidad de Los Andes. Board Member ACEM (Colombian Association of Specialists in Emergency Medicine). Bogota Colombia

\begin{tabular}{|c|c|}
\hline ARTICLE INFO & ABSTRACT \\
\hline 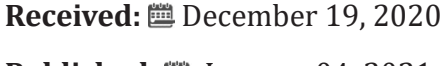 & $\begin{array}{l}\text { Citation: Tatiana Roldan Ovalle. Telemedicine During Covid-19 In Low-Resource Settings. } \\
\text { Biomed J Sci \& Tech Res 32(5)-2021. BJSTR. MS.ID.005321. }\end{array}$ \\
\hline
\end{tabular}

Published: 幽 January 04, 2021

\section{Introduction}

Novel coronavirus disease is posing an extraordinary challenge to the health and well-being of persons across the globe. Along with grave threats to social stability, economic prosperity, and human health, caring for patients places great stress on health care workers [1]. To combat COVID-19, health systems have required immediate injections of public funds to buy equipment, pay for additional staff, and build temporary hospitals. Due to increased government indebtedness and the broader economic impact of COVID-19, a new period of austerity will begin after the pandemic [2]. With anecdotal reports of shortages of supplies and personnel, in many countries such Italy and China, as well as parts of the United States and Colombia, hospital systems have anticipated the sequestering of healthcare resources and personnel [3,4]. COVID-19 will also lead to long-lasting economic effects on health systems by increasing future demand for healthcare services: Because of the necessary resources needed to clear the backlog of postponed elective and semi-elective procedures; Due to the increased burden of disease driven by negative lifestyle changes and poorer mental health; And because of many lost opportunities for primary and secondary prevention of many disease which are known to be cost-effective [2]. But all will also depend the unique context in each country. Many countries are beginning to understand that prolonged austerity has left their healthcare systems vulnerable to major shocks such as this pandemic. However, the ability to maintain health spending growth is also dependent on the state of each country's economy post-pandemic [2].

While this crisis has presented the healthcare systems delivery unprecedented challenges, many countries have catalyzed rapid adoption of telehealth and transformed healthcare delivery at a breathtaking pace [5,6]. The current coronavirus (COVID-19) pandemic is again reminding of the importance of using telehealth to deliver care, especially as means of reducing the risk of crosscontamination caused by close contact $[7,8]$. As the pandemic looms over the country and the health-care community, telemedicine can offer tools to help respond to this crisis. Telemedicine is defined as the remote diagnosis and treatment of patients through telecommunications technology [9]. Healthcare systems leveraging telemedicine for patient care gain several advantages, including workforce sustainability, reduction of provider burnout, limitation of provider exposure, and reduction of personal protective equipment (PPE) waste [10]. Many lessons will inevitably be learned from the COVID-19 crisis. Already, the pandemic has exposed underlying health disparities while also fostering innovative solutions to address health needs in these trying times [11-13].

With these changes, telemedicine is being leveraged with enormous speed and scale, turning into the forward "front line" of the battle against the pandemic [14]. However, telehealth programs 
require adequate broadband access, which is often limited in rural and underserved settings [15]. Inequities in education, poverty, unemployment, economic opportunities and other social determinants contribute to persistent health disparities between those living in rural and urban regions [16]. Rural communities face lower access to healthcare, health services, and health insurance compared to urban settings $[17,18]$. To overcome broadband access issues in rural region, telephonic visits may be offered as a replacement for video visits. [19]. As more providers are now trained and more practices are now equipped with telehealth infrastructure, these services will likely continue to be offered beyond the pandemic. Telehealth may offer several benefits for rural health, including: Providing expanded access to services; Fostering the integration of rural primary care and remote subspecialty services, [19]; And enabling more effective care management [20].

\section{Experience in Colombia}

An experience with a rural area in the country Colombia in South America, is Macedonia, an indigenous reservation located 53 kilometers from Leticia, capital of the Amazonas department in Colombia (Figure 1). The Reservation has an approximate population of 1050 inhabitants, spared into 250 family groups, of which 200 are children, 320 young people, 450 adults and between 70 or 80 older adults, and. Usually, its population subsists on the trade-in handicrafts or tourism. The food is based on their cultivation. Since the beginning of the quarantine determined by the Colombian National Government as a contingency to the coronavirus pandemic, all means of transit and trade by the Amazon river were closed and prohibited, leaving the population without any possibility of getting a minimum income, in a condition of hunger, poverty, and significant vulnerability.

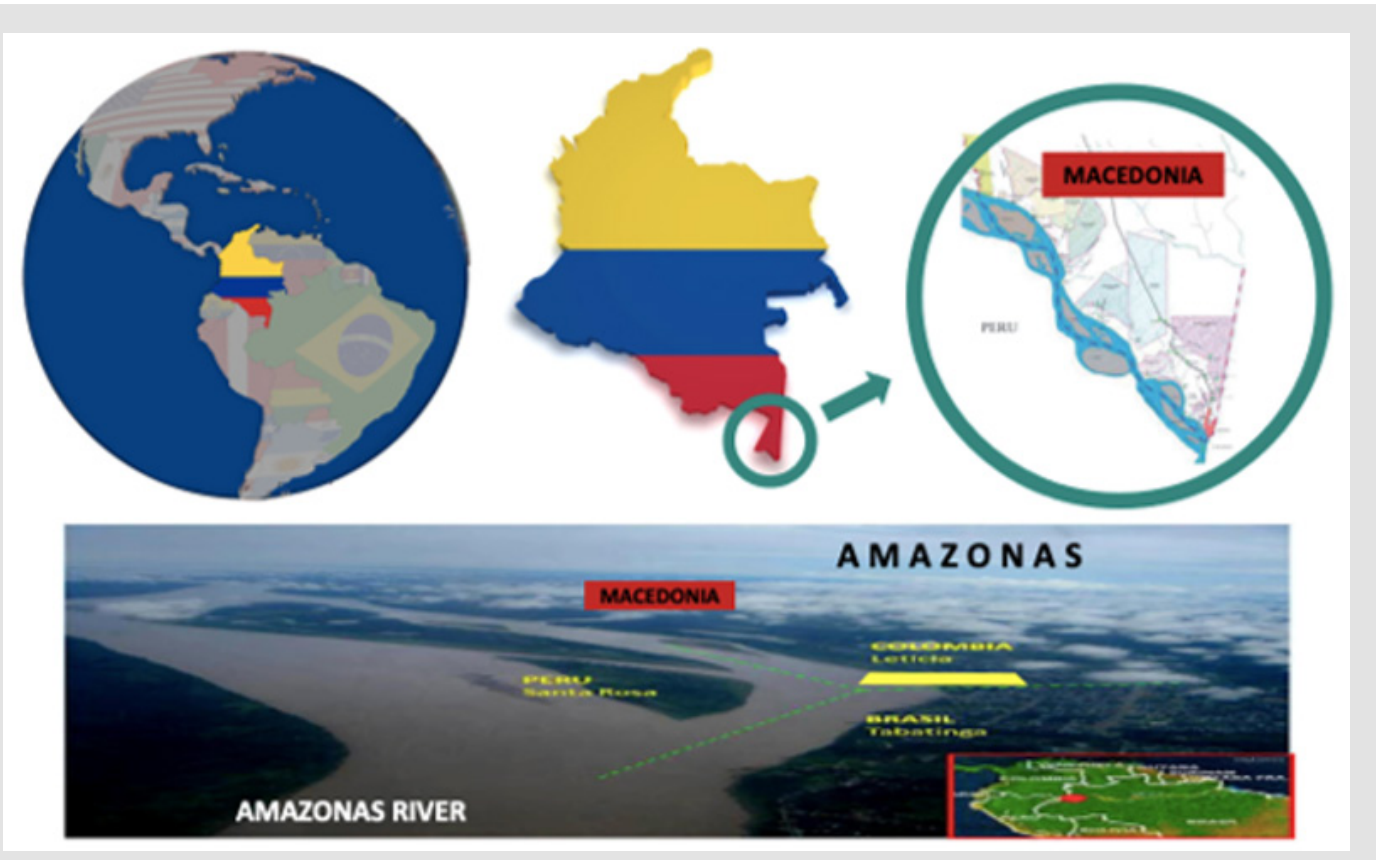

Figure 1: Macedonia - Amazonas department - Colombia.

Half a century of foundation, and, still, there is not a primary health care service, much less any kind of medical dispensary system. Even when entire families began to fall ill in February 2019, they had to resort to the only option known as is the indigenous traditional medicine and the use of plant remedies to reduce the contagion effects for the COVID 19. Nowadays, Macedonia sadly only counts with one health promoter native, who acts as a nursing assistant as well as with two of the elders within the community who are those in charge of caring for the infected and sick using traditional plant remedies and elemental treatments, typical of the Ticuna ethnic group.

Only on one occasion, so far this year, a small brigade, apparently from the department's health secretary, visited this and neighboring communities, to carry out some testing and census of possible infections. Hence, the current indigenous council headmaster also called by the natives as "el Curaca" made known, through the initiative Ticuna Mission Tour (Group of solidarity missionaries, collaborators and friends of the communities of the Amazon Trapezoid) (https://sites.google.com/view/tourmacedonia/ english, s.f.), that at least, two to three people from each family group are either asymptomatic carriers of the virus or have become seriously ill by the COVID 19 . However, they did not receive any medication attention or guidelines to address the detected cases. Fortunately, Ticuna Mission Tour, with its leading Colombian promoter María Fernanda Gómez, with the support of the National Navy of Colombia, were able to take different aids such as food, medicine, clothing and moral support. In consequence, its urgently needed, to supply them with at least a health assistance structure 
which could be developed for example through Telemedicine, since Macedonia, same as the surrounding indigenous communities of the region are in conditions of high vulnerability what could trigger a considerable risk of extinction of the ethnic, cultural heritage so crucial to the hemisphere.

The community Macedonia is characterized by its friendly, healthy, organized, helpful, and hard-working people. Through their community efforts and knowledge, they have adapted a site for future installation of a health dispensary, and by the end of October 2020 the use of broadband and telecommunications access was launched, a project developed by the MinTIC (Colombian Ministry of Information Technologies and Communications), which offered free rural internet connectivity whose initiative will have a guaranteed operation until 2030, ensuring the connection even during the changes of government. Having in mind the mentioned before, is very important acknowledge how does the use of the assistant structure system in healthcare, as is Telemedicine, will notably improve the health service access in rural communities making these latent structures visible that in a normal situation would not be considered.

\section{References}

1. Wu AW (2020) Peer Support and Crisis Communication Strategies to Promote Institutional Resilience. Annals of Internal Medicine 172(12): 822-823.

2. Carter PA, Michael Anderson, Elias Mossialos (2020) Health system, public health, and economic implications of managing COVID-19 from a cardiovascular perspective. European Heart Journal 41 (27): 25162518.

3. Ranney MG (2020) Critical supply shortages-the need for ventilators and personal protective equipment during the covid-19 pandemic. $\mathrm{N}$ Engl J Med 382: e41.

4. Loeb AR, Sandesh S Rao, James R Ficke, Carol D Morris, Lee H Riley. et al. (2020) Departmental Experience and Lessons Learned with Accelerated Introduction of Telemedicine During the COVID-19. Journal of the American Academy of Orthopaedic Surgeons 28 (11): e469-e476.

5. https: //www.healthaffairs.org/\%20 do/ $10.1377 /$ hblog20200315.319008

6. Augenstein J (2020) Opportunities to expand telehealth use amid the coronavirus pandemic.

ISSN: 2574-1241

DOI: 10.26717/BJSTR.2021.32.005321

Khandsuren Badgar. Biomed J Sci \& Tech Res

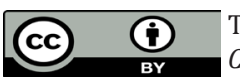

This work is licensed under Creative

Commons Attribution 4.0 License

Submission Link: https://biomedres.us/submit-manuscript.php
7. Galewitz P (2020) Telemedicine surges, fueled by coronavirus fears and shift in payment rules.

8. Wosik JF, Marat Fudim, Blake Cameron, Ziad F Gellad, Alex Cho, et al. (2020) Telehealth transformation COVID-19 and the rise of virtual care. Journal of the American Medical Informatics Association 27(6): 957962.

9. Smith AT, Thomas, Emma, Snoswell, Centaine L, Haydon, et al. (2020) Telehealth for global emergencies: Implications for coronavirus disease 2019 (COVID-19). Journal of Telemedicine and Telecare 26(5): 309-313.

10. Doshi AP, Yonatan Platt, John R Dressen, Benji K Mathews, Jerome C Siy, et al. (2020) Keep Calm and Log On Telemedicine for COVID-19 Pandemic Response . Journal of Hospital Medicine 15(5): 302-304.

11. Hirko KK, Jean M Kerver, Sabrina Ford,Chelsea Szafranski, John Beckett, et al. (2020) Telehealth in Response to the Covid-19 Pandemic Implications for Rural Health disparities.

12. Mann DC, Ji Chen, Rumi Chunara, Paul A Testa, Oded Nov, et al. (2020) COVID-19 transforms health care through telemedicine Evidence from the field. Journal of the American Medical Informatics Association 27(7): $1132-1135$.

13. Bashshur RS, Gary W Shannon (2009) National telemedicine initiatives: Essential to healthcare reform. Telemed J E Health 15: 600-610.

14. Singh G S, Mohammad Siahpush (2014) Widening rural-urban disparities in life expectancy. Am J Prev Med 46(2): e19-29.

15. Laditka JL, Sarah B Laditkaa, Janice C Probst (2009) Health care access in rural areas: evidence that hospitalization for ambulatory care-sensitive conditions in the United States may increase with the level of rurality. Health Place 15(3): 731-740.

16. Probst JM, Charity G Moore, Saundra H Glover, Michael E Samuels (2004) Person and place: the compounding effects of race/ethnicity and rurality on health. Am J Public Health 94(10): 1695-1703.

17. Ray KD, ill R Demirci, Debra L Bogen, Ateev Mehrotra, Elizabeth Miller, et al. (2015) Optimizing telehealth strategies for sub-specialty care: Recommendations from rural pe-diatricians. Telemed e-Health 21(8): 622-629.

18. Myers C (2019) Using Telehealth to Remediate Rural Mental Health and Healthcare Disparities. Ment Health Nurs 40 (3): 233-239.

19. Nagata J (2020) Rapid Scale-Up of Telehealth During the COVID-19 Pandemic and Implications for Subspecialty Care in Rural Areas. The Journal of Rural Health 37(1): 145-145.

20. https://sites.google.com/view/tourmacedonia/english. (s.f.). (T. M. Tour, Productor) Recuperado el 2020, de www.facebook.com: https:// www.facebook.com/Ticuna-Mission-Tour-1775839912435254.

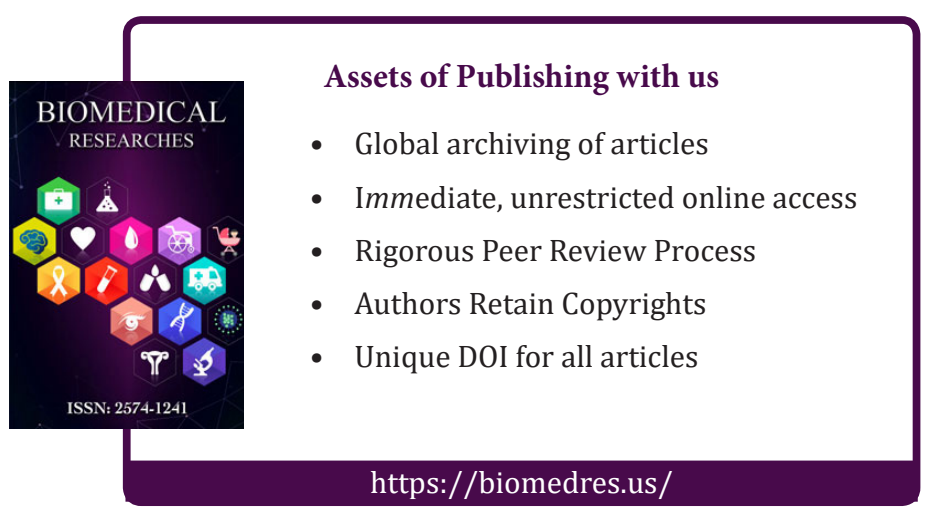

